\title{
Preparation of Manganese Dioxide Nanoparticles on Laterite for Methylene Blue Degradation
}

\author{
Thu-Huong Le, ${ }^{1}$ Thu Hong Anh Ngo ${ }^{D},^{2}$ Van Thuan Doan, ${ }^{3,4}$ Le Minh Tri Nguyen, \\ and Manh Cuong Le $\mathbb{B}^{7}$ \\ ${ }^{1}$ Departerment of Chemistry and Environment, Thuyloi University, Hanoi 100000, Vietnam \\ ${ }^{2}$ Faculty of Chemistry, University of Science, Vietnam National University, 334 Nguyen Trai, Thanh Xuan, Hanoi, Vietnam \\ ${ }^{3}$ NTT Hi-Tech Institute, Nguyen Tat Thanh University, Ho Chi Minh City 700000, Vietnam \\ ${ }^{4}$ Center of Excellence for Green Energy and Environmental Nanomaterials (CEGrEEN), Nguyen Tat Thanh University, \\ Ho Chi Minh City, Vietnam \\ ${ }^{5}$ Laboratory of Advanced Materials Chemistry, Advanced Institute of Materials Science, Ton Duc Thang University, \\ Ho Chi Minh City, Vietnam \\ ${ }^{6}$ Faculty of Applied Sciences, Ton Duc Thang University, Ho Chi Minh City, Vietnam \\ ${ }^{7}$ Faculty of Building Material, National University of Civil Engineering, Hanoi 100000, Vietnam
}

Correspondence should be addressed to Manh Cuong Le; cuonglekhtn@gmail.com

Received 11 March 2019; Revised 30 May 2019; Accepted 25 June 2019; Published 5 September 2019

Academic Editor: Claudia Crestini

Copyright ( 2019 Thu-Huong Le et al. This is an open access article distributed under the Creative Commons Attribution License, which permits unrestricted use, distribution, and reproduction in any medium, provided the original work is properly cited.

\begin{abstract}
The laterite-coating manganese dioxide nanoparticle material (M2) prepared by the immersion method was used for the efficient removal of methylene blue (MB) from aqueous solution. The adsorption and heterogeneous Fenton catalytic oxidation experiments of M2 were investigated by changing the effective factors such as time, $\mathrm{pH}$, amount of M2, and concentration of MB. The adsorption data of M2 showed good fitting with the Langmuir isotherm, suggesting that the adsorption of MB on the surface of M2 is a heterogeneous and physical adsorption process. Degradation of MB was also carried out to evaluate the heterogeneous Fenton catalytic oxidation characterization of a new catalytic oxidation material (M2). The results show that the M2 material has both adsorption and heterogeneous Fenton catalytic oxidation. However, the heterogeneous Fenton catalytic oxidation of the M2 material is the main performance. Hence, our groups have investigated the ability of the catalytic column treatment with high efficiency of $98-100 \%$ and the degradation efficiency after the sample running through the column almost does not change much. This proves that heterogeneous Fenton catalytic activity of the catalytic column is completely unaffected and reused many times after oxidizing MB. Specifically, even if the M2 material is reused for five times, the degradation efficiency still reaches $98.86 \%$.
\end{abstract}

\section{Introduction}

Methylene blue (MB) is an organic compound which used in the treatment of cyanide poisoning, treatment of impetigo, pyoderma, urogenital antiseptic, and dying tissues in some diagnostic operations (bacterial staining, etc.) [1]. In addition, methylene blue is a chemical that is widely used in the dyeing industry of fabrics, nylon, leather, wood, and ink production. Moreover, a large amount of MB remain is in the wastewater of textile dyeing process [2]. Hence, the removal of $\mathrm{MB}$ has attracted considerable attention in the environmental field. Over the past few years, several physical methods and chemical methods have been employed for removing MB [3]. There are several treatment processes that have been applied for treatment of dye wastewater such as photocatalytic degradation $[4,5]$, membrane separation $[5,6]$, adsorption-precipitation processes $[7,8]$, ultrafiltration $[9,10]$, chemical-biological degradation $[6,11]$, Fenton system and heterogeneous Fenton-like catalytic reactions [12-14], and adsorption on activated carbon and electrolysis $[15,16]$. However, some of these techniques are rarely used due to insensitivity to a toxic substance, the complexity of 
the design, and high cost. Therefore, development of an effective, cheap, and eco-friendly method is of crucial importance for the removal of dye wastewater.

Recently, manganese oxide nanoparticles have been also widely used for dye removal due to the effect of the chemical and physical interactions which occur between the organic (polymer) and inorganic (manganese dioxide nanoparticles) components $[17,18]$. Manganese dioxide nanoparticles material is not only nontoxic but also has highly active and strong oxidations because the oxidation number of $\mathrm{Mn}$ is +4 . In addition, manganese oxide nanoparticles have been used as adsorbents and catalytic materials [19-22]. Hence, most research focus on investigating the ability of Fenton catalytic oxidation of manganese oxide, especially manganese dioxide $\left(\mathrm{MnO}_{2}\right)$, for degradation of dye molecules. Dantas et al. [23] studied the ability of catalytic oxidation reaction of methylene blue with $\mathrm{H}_{2} \mathrm{O}_{2}$ under catalysts of $\beta-\mathrm{MnOOH}, \alpha$-FeOOH, $\gamma$ $\mathrm{Mn}_{3} \mathrm{O}_{4}$, and treated methylene blue at $30 \mathrm{mg} / \mathrm{L}$ in 40 minutes. In addition, Zhang et al. [24] synthesized $\beta-\mathrm{MnO}_{2}$ with size about $30-400 \mathrm{~nm}$ and applied $\beta-\mathrm{MnO}_{2}$ to form bars and columns, with the surface area of $68.82 \mathrm{~m}^{2} / \mathrm{g}$, as a catalyst to remove methylene blue. The degradation percentage of methylene blue using $\beta-\mathrm{MnO}_{2}$ is $100 \%$ in 40 minutes. Furthermore, Liangjie Yuan [1] studied the ability of the catalyst carbon nanometre coated $\mathrm{MnO}_{2}$ to treat $\mathrm{MB}$ by adding $\mathrm{H}_{2} \mathrm{O}_{2}$ agent. In addition, Yang et al. [2] also studied the ability of the catalysts to remove hexanol of amorphous $\mathrm{MnO}_{2}$ oxide and pyroluzite $\left(\beta-\mathrm{MnO}_{2}\right)$. The study found that $99 \%$ of hexanol was treated in 60 minutes. Han et al. [25] also synthesized $\mathrm{Mn}_{3} \mathrm{O}_{4} / \mathrm{SBA}-15$ to treat ethanol with a concentration of $100 \mathrm{ppm}$ under the $\mathrm{H}_{2} \mathrm{O}_{2}$ agent. The study of Han et al. group and Liangjie Yuan group also demonstrated that manganese oxide nanoparticles are a oxidation catalytic to induce free radicals $\mathrm{OH}^{*}, \mathrm{O}_{2}^{*}$, and $\mathrm{HO}_{2}^{*}$, leading to potential application of it in heterogeneous Fenton catalytic. Thus, manganese dioxide nanoparticles are not only degradation MB by physical adsorption but also degradation MB by heterogeneous Fenton catalytic oxidation. However, the use of manganese dioxide nanoparticles has several disadvantages due to self-aggregation, difficulty in solid-liquid separation, and leaching of nanoparticles with the treated effluents. These limitations can be avoided by anchoring the particle on the substrates with high sorption capacity of adsorbents and Fenton catalytic activity such as laterite ore. Therefore, manganese oxide nanoparticles were then mixed with denaturized laterite (iron-rich ore, available in Vietnam) to create new highperformance materials because impregnation or coating with nanoparticles enhances the sorption capacity of adsorbents and Fenton catalytic activity. Therein, the manganese oxide nanoparticle is the catalysts effective material, and the laterite is the adsorption efficiency material for degradation MB. Therefore, the combination of these two effective materials can result in the best adsorbent and catalytic oxidation material for $\mathrm{MB}$ removal. The objectives of this study are to synthesize colloidal manganese dioxide nanoparticles $\left(\mathrm{MnO}_{2}\right.$ NPs), to prepare mixed material by mixing colloidal $\mathrm{MnO}_{2}$ NPs and denaturized laterite, and to investigate the adsorption and heterogeneous Fenton catalysts of the mixed material for $\mathrm{MB}$ removal.

\section{Materials and Methods}

2.1. Chemicals and Characterization. All chemical reagents, including manganese sulfate monohydrate $\left(\mathrm{MnSO}_{4} \cdot \mathrm{H}_{2} \mathrm{O}\right)$, potassium permanganate $\left(\mathrm{KMnO}_{4}\right)$, hydrogen peroxide $\left(\mathrm{H}_{2} \mathrm{O}_{2}\right)$, ethanol $\left(\mathrm{C}_{2} \mathrm{H}_{5} \mathrm{OH}, 99.5 \%\right)$, polyvinyl alcohol (PVA, $\left.M_{\mathrm{w}} \sim 31,000\right)$, and methylene blue, were purchased from Merck. In our experiment, we use laterite ore from Cao Bang Province, VietNam.

X-ray diffraction (XRD) spectra of absorption materials were obtained using D8 Advance (Bruker, Germany) and D5005 (Siemens, Germany). The scanning electron microscopy and energy dispersive $\mathrm{X}$-ray spectroscopy (EDX) were performed with S-4800 (SEM, Hitachi). The transmission electron microscopy (TEM) was performed with a JEOL JEM 1010 operated at $80 \mathrm{kV}$. UV-Vis absorption spectra were obtained on an UV1800, Japan.

2.2. Synthesis of Colloidal Manganese Dioxide Nanoparticles $\left(\mathrm{MnO}_{2} \mathrm{NPs}\right)$. The colloidal $\mathrm{MnO}_{2} \mathrm{NPs}$ are synthesized as shown in Scheme1 [26]. $6 \mathrm{~mL}$ of the diluted potassium permanganate $\left(\mathrm{KMnO}_{4} 0.5 \mathrm{M}\right)$ solution was added into $100 \mathrm{~mL}$ mixture solvent of EtOH: $\mathrm{H}_{2} \mathrm{O}(1: 1)$ at room temperature. The mixture was stirred, and then 10\% $\mathrm{H}_{2} \mathrm{O}_{2}$ and polyvinyl alcohol (PVA) were added. The polyvinyl alcohol (PVA) was used a coreduction agent to obtain $\mathrm{MnO}_{2}$. Soon after adding $10 \% \mathrm{H}_{2} \mathrm{O}_{2}$ and polyvinyl alcohol (PVA), the brown precipitate began to appear. The brown precipitate was collected by centrifugation and washed with ethyl alcohol (three times). To remove polyvinyl alcohol (PVA), the mixture was precipitated with ethanol as a solvent and hexane as an antisolvent. Finally, colloidal $\mathrm{MnO}_{2}$ NPs were obtained as brown powder.

2.3. Preparation of Laterite-Based Materials. The laterite ore was collected from Cao Bang Province, Vietnam. The laterite ore was crushed and sieved. The fraction small laterite particle is thermally denatured by following the procedure in Scheme2. $100 \mathrm{~g}$ of laterite powder was treated with $40 \mathrm{~mL}$ of $\mathrm{HCl}$ in a $250 \mathrm{~mL}$ beaker. The mixtures were soaked for 2 hours and then decant a liquid. The remaining powder was rinsed with distilled water and dried at $100^{\circ} \mathrm{C}$. Finally, we obtained the substrate material, referred to as M1.

2.4. Preparation of Mixed. In the final step, the prepared colloidal $\mathrm{MnO}_{2} \mathrm{NPs}$ were mixed with denaturized laterite by the immersion method. $50 \mathrm{~g}$ of the denaturized laterite particle $(0.5 \mathrm{~mm})$ was added into the beaker which contained the colloidal $\mathrm{MnO}_{2} \mathrm{NPs}$. The mixture was impregnated for 12 hours and then dried at $105^{\circ} \mathrm{C}$ for 8 hours. The power was rinsed by distilled water to remove the remaining salt. Finally, we obtained the mixed absorbent material symbolized as M2. 


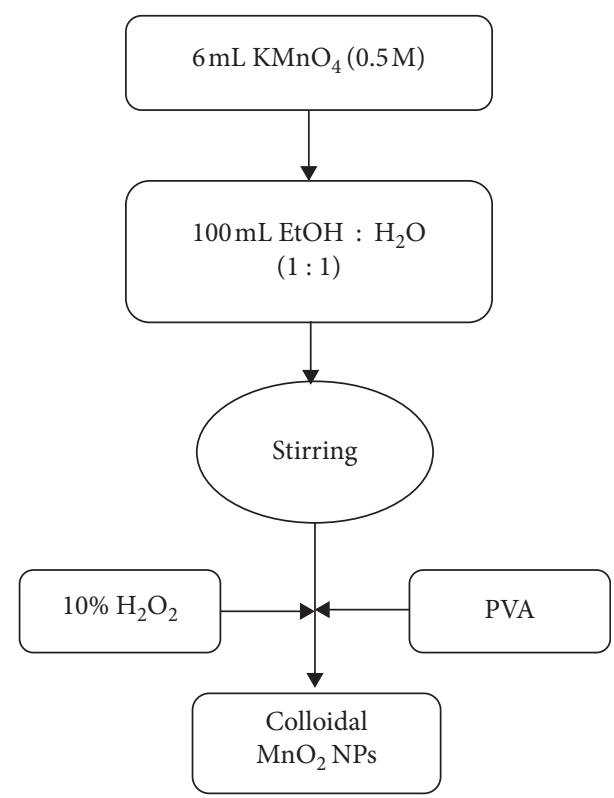

Scheme 1: Synthesis of colloidal $\mathrm{MnO}_{2}$ NPs.

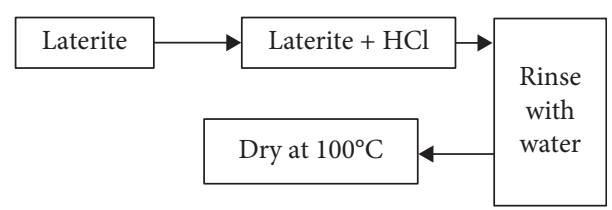

Scheme 2: Thermal denaturation of laterite ore.

To determine the shape, phase composition, particle size, particle distribution of colloidal $\mathrm{MnO}_{2} \mathrm{NPs}$ (M1), and M2 materials, we use the transmission electron microscopy (TEM), scanning electron microscopy (SEM), and X-ray diffraction (XRD) pattern (XRD) analysis.

The adsorptive and catalytic activities of the mixed material (M2) were assessed by using methylene blue. The methylene blue concentrations before and after treatment were determined by the absorption intensity of the UV spectrum at the maximum absorption wavelength of $664 \mathrm{~nm}$, which is explained in detail in Supplementary Materials.

2.5. Adsorption Experiments. Adsorption experiments were investigated by changing the effective factors such as time, $\mathrm{pH}$, and concentration of methylene blue (MB). The residual concentration of $\mathrm{MB}$ was determined with the help of the calibration plot of $\mathrm{MB}$ solution at a fixed wavelength $(667 \mathrm{~nm})$ with varying initial ion metal concentration which is explained in detail in Supplementary Materials. The amount of adsorbed $\mathrm{MB}\left(C_{\mathrm{a}} \mathrm{mg} / \mathrm{L}\right)$ was found out using the following formula [27]:

$$
C_{\mathrm{a}}=C_{0}-C_{\mathrm{e}}(\mathrm{mg} / \mathrm{L}),
$$

where $C_{0}$ is the initial concentration and $C_{\mathrm{e}}$ is the residual concentration of $\mathrm{MB}$. The adsorption percentage was calculated by the following equation:

$$
\text { Adsorption }(\%)=\frac{C_{a}}{C_{0}} \times 100,
$$

where $C_{\mathrm{a}}$ is the adsorbed concentration $(\mathrm{mg} / \mathrm{L})$ of $\mathrm{MB}$ and $C_{0}$ is the initial concentration of MB.

The equilibrium adsorption capacities of M2 for methylene blue $(\mathrm{MB})$ were calculated by the following equation [27]:]:

$$
q_{\mathrm{e}}=\frac{V_{0}\left(C_{0}-C_{\mathrm{e}}\right)}{m}
$$

where $q_{\mathrm{e}}$ is the equilibrium adsorption capacity $(\mathrm{mg} / \mathrm{g}), C_{0}$ and $C_{\mathrm{e}}$ are the initial and residual concentrations $(\mathrm{mg} / \mathrm{L})$ of $\mathrm{MB}$ solution, respectively, $V_{0}$ is the volume of the initial solution ( $L$ ) use for sorption, and $m$ is the weight of the adsorbent (g).

2.5.1. Determination of Equilibrium Time. The equilibrium time was determined by taking $1.0 \mathrm{~g}$ of the adsorbent M2 with $100 \mathrm{~mL} \mathrm{MB}(80 \mathrm{mg} / \mathrm{L})$ solution at $\mathrm{pH}$ equal to 7 , followed by stirring at room temperature at various time intervals ranging from 0 to $7 \mathrm{~h}$.

2.5.2. Adsorption Isotherm. The adsorption isotherms of MB were investigated by taking $1.0 \mathrm{~g}$ of M2 material with $100 \mathrm{~mL}$ of $\mathrm{MB}$ solution with different initial concentrations (varying from 10 to $300 \mathrm{mg} / \mathrm{L}$ ) at $\mathrm{pH}$ about 7 under room temperature with stirring for 6 hours.

2.5.3. Kinetic Adsorption Experiment. The adsorption kinetic is described by the Langmuir adsorption model and the Freundlich adsorption model. The Langmuir equation is generally expressed as follows [28]:]:

$$
\frac{1}{q_{\mathrm{e}}}=\frac{1}{q_{\max } K_{\mathrm{L}} C_{\mathrm{e}}}+\frac{1}{q_{\max }},
$$

where $q_{\mathrm{e}}$ and $q_{\max }$ are the equilibrium adsorption capacity and a maximum capacity of adsorbent $(\mathrm{mg} / \mathrm{g})$, respectively, $C_{\mathrm{e}}$ is the equilibrium $\mathrm{MB}$ concentration in solution $(\mathrm{mg} / \mathrm{L})$, and $K_{\mathrm{L}}$ is the Langmuir adsorption constant pertaining to the energy of adsorption ( $\mathrm{L} / \mathrm{mg})$. [28]:

The Freundlich equation is generally expressed as follows

$$
\lg q_{\mathrm{e}}=\lg K_{\mathrm{F}}+\frac{1}{n_{\mathrm{F}}} \lg C_{\mathrm{e}},
$$

where $n=1 / n_{f^{\prime}}$ is the slope of Freundlich isotherm and $K_{\mathrm{L}}$ is the Freundlich adsorption constant.

2.6. Heterogeneous Fenton Catalytic Oxidation Experiments. Degradation of MB was carried out to evaluate the heterogeneous Fenton catalytic oxidation characterization of a new catalytic oxidation material (M2). Sodium hydroxide and hydrochloric acid were used for modifying the $\mathrm{pH}$ of the solutions. 30\% hydrogen peroxide was used as the oxidation agent to enhance the degradation of MB. The degradation experiments were performed as a function of time, $\mathrm{pH}$ of $\mathrm{MB}$ 
solution, and the amount of $30 \%$ hydrogen peroxide under room temperature. The degradation percentage of $\mathrm{MB}$ was calculated according to the following equation [1]:

$$
\text { degradation }(\%)=\frac{C_{0}-C_{\mathrm{e}}}{C_{0}} \times 100,
$$

where $C_{0}$ is the initial concentration of $\mathrm{MB}$ solution and $C_{\mathrm{e}}$ is the residual concentration of $\mathrm{MB}$ solution after treating with the catalyst oxidation material M2.

2.6.1. Effect of Amount of Hydrogen Peroxide. The effect of amount of $30 \% \mathrm{H}_{2} \mathrm{O}_{2}$ on the degradation of methylene blue (MB) was evaluated by stirring $1.0 \mathrm{~g}$ M2 material with $100 \mathrm{~mL}$ of $\mathrm{MB}$ solution $(20 \mathrm{mg} / \mathrm{L})$ for various volumes of $30 \% \mathrm{H}_{2} \mathrm{O}_{2}$ solution from 0.2 to $5 \mathrm{~mL}$, at $\mathrm{pH} 7.0$, followed by stirring for $45 \mathrm{~min}$. Then, the $\mathrm{MB}$ solutions were separated by centrifugation to determine the methylene blue concentration by using the UV-Vis spectrophotometer.

2.6.2. Effect of Time. The effect of time on the degradation of $\mathrm{MB}$ was evaluated by stirring $1.0 \mathrm{~g} \mathrm{M} 2$ material and adding $1.5 \mathrm{~mL} 30 \% \mathrm{H}_{2} \mathrm{O}_{2}$ and $100 \mathrm{~mL}$ of $\mathrm{MB}$ solution $(20 \mathrm{mg} / \mathrm{L})$ at various time intervals ranging from 0 to $180 \mathrm{~min}$, at $\mathrm{pH}$ 7.0. Then, the MB solutions were separated by centrifugation to determine the methylene blue concentration by using the UV-Vis spectrophotometer.

2.6.3. Effect of $p H$. The effect of $\mathrm{pH}$ of metal ion solutions on degradation of $\mathrm{MB}$ was examined. $1.0 \mathrm{~g}$ of M2 material was added to $100 \mathrm{~mL}$ of $\mathrm{MB} 20 \mathrm{mg} / \mathrm{L}$ solution with varying $\mathrm{pH}$ values ranging from 2 to 12 , at room temperature, followed by stirring for $45 \mathrm{~min}$. The $\mathrm{pH}$ of metal ion solutions was adjusted to the desired value by using $\mathrm{HCl} 0.1 \mathrm{M}$ or $\mathrm{NaOH}$ $0.1 \mathrm{M}$.

2.6.4. Effect of Catalyst Oxidation Material M2 Mass. The effect of amount of M2 on the degradation of MB was tested by stirring different amounts of $\mathrm{M} 2(0.2,1.0,1.5,2.0$, 2.5, 3.0, 3.5, 4.0, and $5.0 \mathrm{~g}$ ) and adding $1.5 \mathrm{~mL} 30 \% \mathrm{H}_{2} \mathrm{O}_{2}$ and $100 \mathrm{~mL}$ of $\mathrm{MB}$ solution $(20 \mathrm{mg} / \mathrm{L})$ at $\mathrm{pH} 7.0$, followed by stirring for $45 \mathrm{~min}$. Then, the MB solutions were separated by centrifugation to determine the methylene blue concentration by using the UV-Vis spectrophotometer.

\section{Results and Discussion}

3.1. Characterization of Colloidal $\mathrm{MnO}_{2} \mathrm{NPs}$, Laterite, and Mixed Material (M2). Figure 1 shows the transmission scanning electron microscopy (TEM) image of colloidal $\mathrm{MnO}_{2}$ NPs. The average sizes of the $\mathrm{MnO}_{2}$ NPs are about $50 \mathrm{~nm}$. The TEM image clearly shows that the spherical particle of $\mathrm{MnO}_{2}$ NPs sample is formed, and their size distribution is narrow. Moreover, the TEM results of $\mathrm{MnO}_{2}$ NPs sample show those particles which aggregate to form a block with a porous structure.

The surface structures of laterite (M1) and mixed material (M2) were analysed by the scanning electron

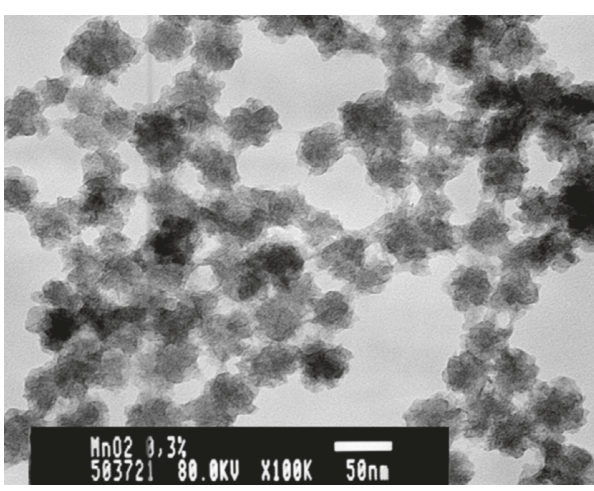

FIgURE 1: TEM micrograph of $\mathrm{MnO}_{2}$ nanoparticles.

microscopy (SEM) in Figures 2(a) and 2(b). The SEM results show that the surface of the laterite after the immersion process has been coated by the nanoparticle layer. In addition, the average sizes of laterite particles are about $5 \mathrm{~mm}$ in Figure 2(a). Therefore, we believe that the nanoparticle layer is $\mathrm{MnO}_{2} \mathrm{NPs}$, which coats on the laterite surface.

Figure 3 shows X-ray diffraction (XRD) patterns of M1, $\mathrm{MnO}_{2} \mathrm{NPs}$, and $\mathrm{M} 2$ materials. The XRD results of laterite (M1) and laterite after coating with $\mathrm{MnO}_{2}$ nanoparticle (M2) showed some similar main peaks at $2 \theta$ of $24.2,34.1,35.8$, $54.6,62.7,21.0,26.7,50.10$, and $60^{\circ}$ which were associated with hematite and quartz [29]. In addition, the XRD result of $\mathrm{MnO}_{2}$ NPs does not show any peaks. Thus, these results prove that the $\mathrm{MnO}_{2}$ NPs layer coats on laterite in an amorphous structure.

The composition of the laterite after coating $\mathrm{MnO}_{2}$ nanoparticle (M2) is also analysed by energy dispersive $\mathrm{X}$-ray spectroscopy (EDX). Figure 4 shows that these M2 materials are composed of mainly Fe element (from $\mathrm{Fe}_{2} \mathrm{O}_{3}$ ), $\mathrm{Si}$ element (from the $\mathrm{SiO}_{2}$ ), $\mathrm{Al}$ element (from the $\mathrm{Al}_{2} \mathrm{O}_{3}$ ), $\mathrm{O}$ element (from $\mathrm{Fe}_{2} \mathrm{O}_{3}, \mathrm{SiO}_{2}$, and $\mathrm{Al}_{2} \mathrm{O}_{3}$ ), and $\mathrm{S}$ element. Furthermore, the manganese element is detected in the EDX result which shows that $\mathrm{MnO}_{2} \mathrm{NPs}$ had been coated on the surface of the laterite particle.

\subsection{The Adsorption of the Mixed Material (M2)}

3.2.1. Effect of Time. The adsorption process is time dependent, as shown in Figure 5 and Table S1 (Supplementary materials). The results of MB showed that when increasing the adsorption time, the adsorption percentage increased. In Figure 5, adsorption occurs rapidly in the first 5 hours, and then the adsorption rate slowed down and almost reached equilibrium at 6 hours. Hence, 6 hours have to be considered as an optimized time for the adsorption of MB.

The adsorption isotherms of $\mathrm{MB}$ were investigated by taking $1.0 \mathrm{~g}$ of M2 adsorbent material with $100 \mathrm{~mL}$ of MB solution with different initial concentrations (varying from 20 to $100 \mathrm{mg} / \mathrm{L}$ ) at $\mathrm{pH}$ of about 7 under room temperature with stirring for 6 hours. The results in Table S4 (Supplementary materials) show that when the concentration of $\mathrm{MB}$ gradually increases, the adsorption capacity increases and the percentage decreases. 


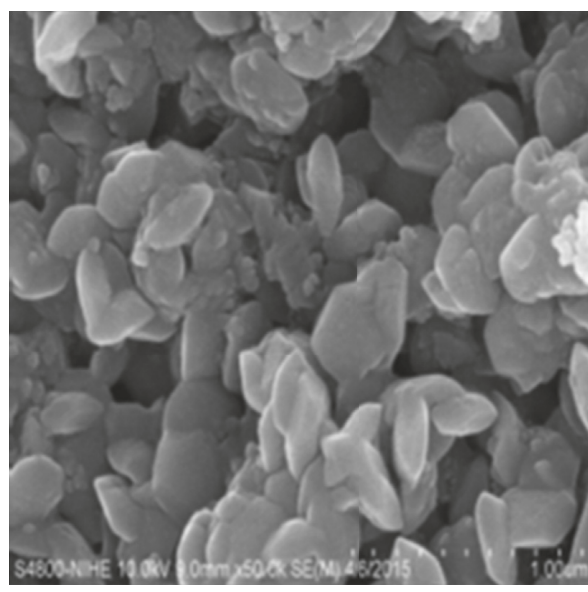

(a)

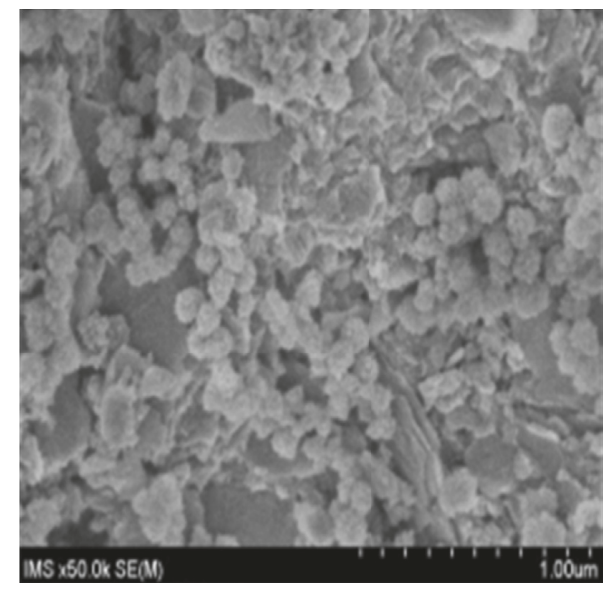

(b)

FIGURE 2: SEM micrographs of (a) laterite (M1) and (b) laterite after coating with $\mathrm{MnO}_{2}$ nanoparticles (M2).

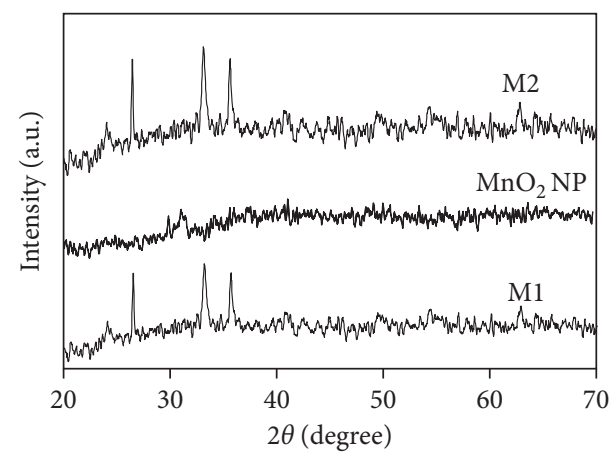

Figure 3: Powder X-ray diffraction pattern of $\mathrm{M} 1, \mathrm{MnO}_{2} \mathrm{NP}$, and M2 samples.

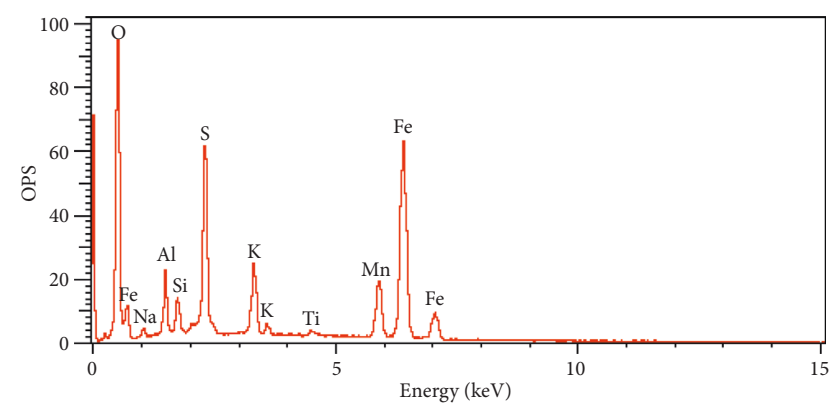

FIgUre 4: Energy-dispersive X-ray (EDX) spectra of the mixed laterite after $\mathrm{MnO}_{2} \mathrm{NP}(\mathrm{M} 2)$ coating.

3.2.2. Adsorption Isotherm. The adsorption kinetic is described by the Langmuir adsorption model and the Freundlich adsorption model [28]. The linear equation was used to fit the $\mathrm{MB}$ adsorption process on $\mathrm{M} 2$, as shown in Figures 6(a) and 6(b) and Table S2 (Supplementary materials). The Langmuir adsorption isotherm assumes that the monolayer adsorption occurs on a homogeneous surface of the adsorbent, while Freundlich adsorption isotherm assumes that the multilayer adsorption occurs on a heterogeneous surface of the adsorbent. Results show that the Freundlich model $\left(R^{2}=0.966\right)$ is better than the Langmuir

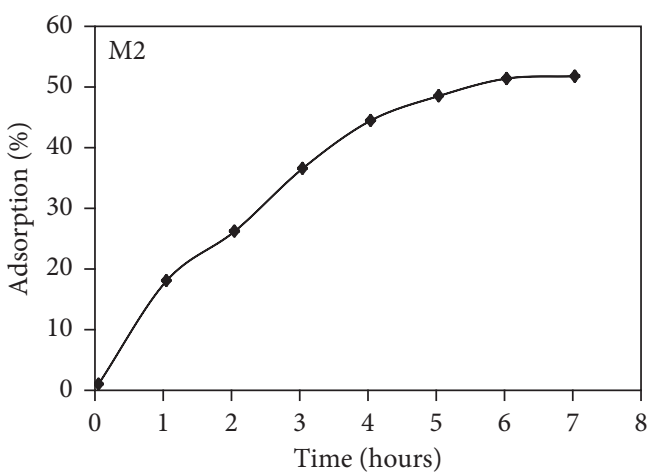

Figure 5: Effect of time on the adsorption process of MB.

model $\left(R^{2}=0.8717\right)$ in simulating the adsorption experiments. This suggests that the adsorption process is a heterogeneous process. The maximum adsorption capacity for $\mathrm{MB}$ was $10.63 \mathrm{mg} / \mathrm{g}$. The $n_{\mathrm{F}}$ value in the Freundlich equation (Table 1) is used to determine adsorption whether it is linear adsorption $\left(n_{\mathrm{F}}=1\right)$, chemical adsorption $\left(n_{\mathrm{F}}<1\right)$, or physical adsorption $\left(n_{\mathrm{F}}>1\right)$ [28]. Moreover, the adsorption of M2 on $\mathrm{MB}$ powder is the physical adsorption process due to the $n_{\mathrm{F}}$ value $\left(n_{\mathrm{F}}=2.6\right)$ larger than 1 (Table 1$)$.

Moreover, to assess the adsorption performance of laterite after coating $\mathrm{MnO}_{2} \mathrm{NP}$ material (M2) in environmental treatment, our group investigated large-scale survey adsorption performance by preparing one adsorption column with a diameter of $15 \mathrm{~cm}$, height of $15 \mathrm{~cm}$, and weight of M2 material about $50 \mathrm{~g}$. The ability absorption MB of the column was carried out with the initial concentration of methylene blue $40 \mathrm{mg} / \mathrm{L}$ and flow rate $2 \mathrm{~mL} / \mathrm{min}$. The results of column processing absorption are given in Table 2 .

The results of Table 2 show adsorption performance of the laterite-coating $\mathrm{MnO}_{2} \mathrm{NP}$ material (M2). These results suggest the $\mathrm{MB}$ adsorption over the laterite after coating $\mathrm{MnO}_{2} \mathrm{NPs}$ (M2) proceeds rather through weak and physical type adsorption than chemical type adsorption. Moreover, the adsorption time reached equilibrium at 6 hours with low adsorption percentage of $\mathrm{MB}$ of $50 \%$. 


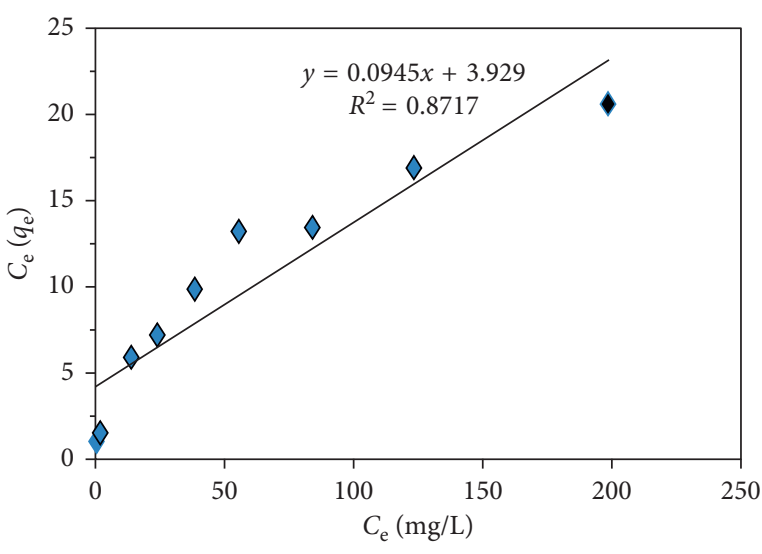

(a)

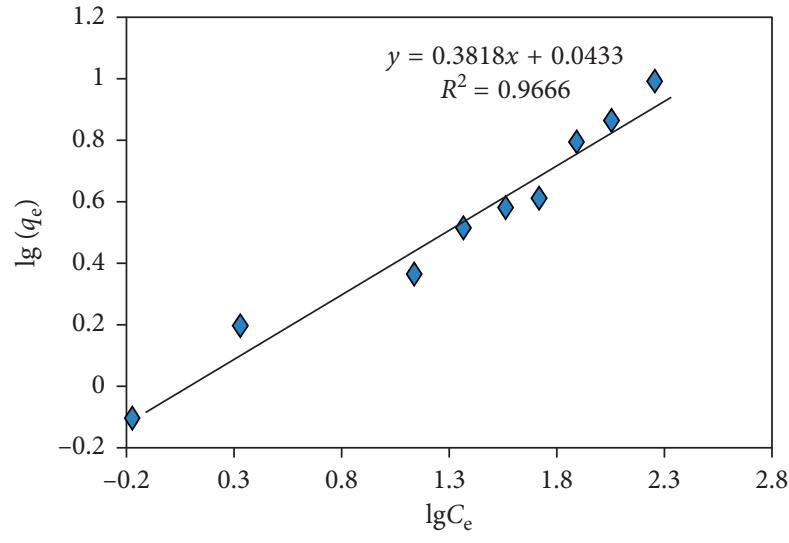

(b)

Figure 6: Adsorption isotherm of MB: (a) Langmuir isotherm and (b) Freundlich isotherm.

TABle 1: Kinetic parameter and correlation coefficient of two kinetic equations.

\begin{tabular}{lccccc}
\hline & Langmuir & & \multicolumn{3}{c}{ Freundlich } \\
$K_{\mathrm{L}}(\mathrm{L} / \mathrm{mg})$ & $q_{\max }(\mathrm{mg} / \mathrm{g})$ & $R^{2}$ & $n_{\mathrm{F}}$ & $K_{\mathrm{F}}$ & $R^{2}$ \\
\hline 0.024 & 10.6 & 0.871 & 2.6 & 1.10 & 0.966 \\
\hline
\end{tabular}

TABLE 2: Results of the large-scale surveys on adsorption performance of M2.

\begin{tabular}{lcc}
\hline No. & $V(\mathrm{~mL})$ & Output concentration of MB $(\mathrm{mg} / \mathrm{L})$ \\
\hline 1 & 2000 & - \\
2 & 1000 & 0.2 \\
3 & 900 & 0.91 \\
4 & 800 & 1.35 \\
5 & 700 & 3.79 \\
6 & 600 & 5.11 \\
7 & 400 & 8.77 \\
8 & 200 & 16.66 \\
9 & 100 & 27.80 \\
10 & 50 & 33.79 \\
11 & 25 & 36.84 \\
12 & 15 & 38.01 \\
13 & 10 & 39.17 \\
14 & 5 & 40.00 \\
\multicolumn{3}{r}{ Amount of methylene blue absorbed on column is $2.51 \mathrm{~g}$}
\end{tabular}

\subsection{The Catalytic Oxidation Activity of the Mixed Material (M2)}

3.3.1. Effect of $\mathrm{H}_{2} \mathrm{O}_{2}$ Concentration. As mentioned above, thanks to the outstanding advantage of removing organic pollutants, the highly biodegradable organic matter (POP) enhanced the oxidation process based on free radicals $\mathrm{HO}^{*}$ of $\mathrm{H}_{2} \mathrm{O}_{2}$, which is considered a "key gold" to solve the challenging problems of the century for the current water and wastewater treatment industries. Thus, we investigate the effect of $\mathrm{H}_{2} \mathrm{O}_{2}$ concentration on the degradation of $\mathrm{MB}$ in Figure 7. In Figure 7 and Table S3 (Supplementary materials), the effect of hydrogen peroxide concentration on the degradation of methylene blue shows that in the range of 0.2

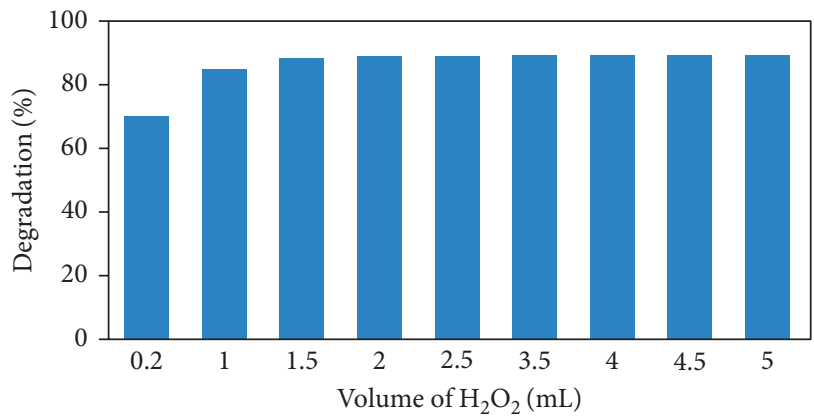

FIGURE 7: Effect of the hydrogen peroxide concentration on the degradation percentage of $\mathrm{MB}$.

to $1.5 \mathrm{~mL}$ of $30 \% \mathrm{H}_{2} \mathrm{O}_{2}$, the degradation percentage increases strongly from 70 to $89.01 \%$. Thus, $\mathrm{MB}$ efficiency degradation is proportional to the concentration of $\mathrm{H}_{2} \mathrm{O}_{2}$. This result is explained by the increase in the number of free radicals $\left(\mathrm{HO}^{*}\right.$ ) generated from $\mathrm{H}_{2} \mathrm{O}_{2}$ over the laterite after $\mathrm{MnO}_{2} \mathrm{NP}$ (M2) catalyst coating.

When the amount of $\mathrm{H}_{2} \mathrm{O}_{2}$ increased over $1.5 \mathrm{~mL}$, the excessive $\mathrm{H}_{2} \mathrm{O}_{2}$, reacts with the availability of $\mathrm{HO}^{*}$ to release the hydroperoxyl radicals $\left(\mathrm{HOO}^{*}\right)$ (Equation (7)). Moreover, the hydroperoxyl radicals $\left(\mathrm{HOO}^{*}\right)$ react immediately with $\mathrm{HO}^{*}$ (Equation (8)) to induce $\mathrm{H}_{2} \mathrm{O}$ and $\mathrm{O}_{2}$ (Equation (8)) resulting in a reduction of the availability of $\mathrm{HO}^{*}$ [30].

$$
\begin{gathered}
\mathrm{H}_{2} \mathrm{O}_{2}+\mathrm{HO}^{*} \longrightarrow \mathrm{HOO}^{*}+\mathrm{H}_{2} \mathrm{O} \\
\mathrm{HO}_{2}^{*}+\mathrm{HO}^{*} \longrightarrow \mathrm{H}_{2} \mathrm{O}+\mathrm{O}_{2}
\end{gathered}
$$

The consumption of free radical $\mathrm{HO}^{*}$ reduced the catalytic ability, leading to reduction in the efficiency of treatment. Thus, it can be seen that the optimal amount of $\mathrm{H}_{2} \mathrm{O}_{2}$ for methylene blue treatment is $1.5 \mathrm{~mL}$ of $30 \%$ $\mathrm{H}_{2} \mathrm{O}_{2}$.

3.3.2. Effect of Time. The survey results of the effect of time (Figure 8 and Table S4 (Supplementary materials)) show that 


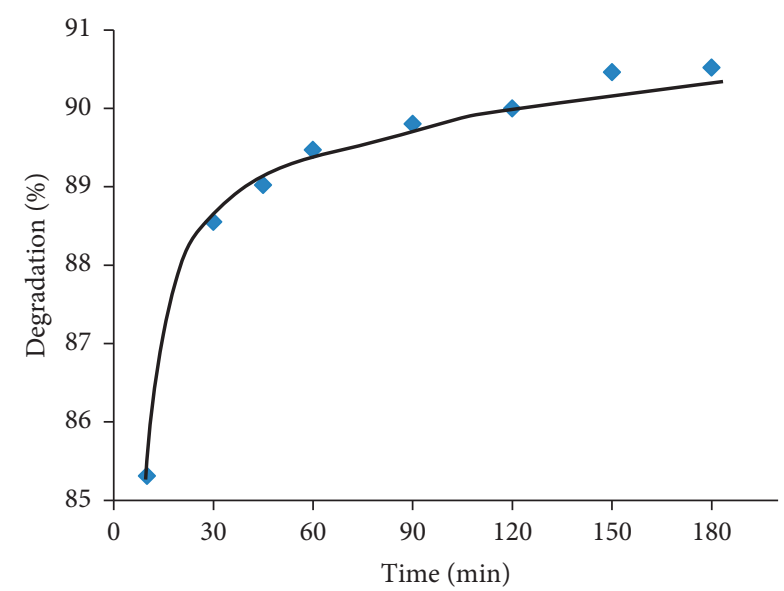

FiguRE 8: Effect of time on the degradation percentage of MB.

the first $45 \mathrm{~min}$ of processing speed increased rapidly and reached a quite high efficiency of $89.96 \%$ and then increased slowly. Thus, during the next survey, it is recommended to select the optimal time of $45 \mathrm{~min}$.

3.3.3. Effect of $p H$. The $\mathrm{pH}$ of the solution plays an important role in determining the adsorption ability of $\mathrm{M} 2$ for methylene blue. The effect of $\mathrm{pH}$ on the $\mathrm{MB}$ removal was investigated at a $\mathrm{pH}$ range of $2-12$. The results obtained are presented in Figure 9 and Table S5 (Supplementary materials). The results of surveying the effect of $\mathrm{pH}$ show that when the $\mathrm{pH}$ was $2-5$, the $\mathrm{MB}$ degradation efficiency was low. When the $\mathrm{pH}$ is from 6 to 8 , the degradation efficiencies of $\mathrm{MB}$ increase strongly from 80 to $89 \%$. Especially, the maximum degradation efficiency of $\mathrm{MB}$ is $100 \%$ in the $\mathrm{pH}$ region of 9-12. Therefore, we choose $\mathrm{pH} 7$ for further studies.

3.3.4. Effect of Catalyst Dosage. The effect of the amount of the laterite after $\mathrm{MnO}_{2} \mathrm{NP}$ (M2) catalyst coating on the removal of methylene blue is investigated and is shown in Figure 10 and Table S6 (Supplementary materials). The result shows that the degradation efficiency increases with increasing catalyst content, due to the increase in the catalytic active sites on the surface of the catalyst and the associated generated free hydroxyl radicals (equations (9)-(12)) $[29,30]$. Especially, the degradation efficiency increases rapidly in the range of 0.5 to $1.5 \mathrm{~g}$ of M2 (Figure 10):

$$
\begin{gathered}
\mathrm{H}_{2} \mathrm{O}_{2}+\mathrm{Fe}^{3+} \longrightarrow \mathrm{Fe}(\mathrm{HOO})^{2+}+\mathrm{H}^{+} \\
\mathrm{Fe}(\mathrm{HOO})^{2+} \longrightarrow \mathrm{Fe}^{2+}+\mathrm{HOO}^{*} \\
\mathrm{Fe}^{2+}+\mathrm{H}_{2} \mathrm{O}_{2} \longrightarrow \mathrm{Fe}^{3+}+\mathrm{OH}^{*} \\
\mathrm{H}_{2} \mathrm{O}_{2} \stackrel{\mathrm{MnO}_{2}}{\longrightarrow} \mathrm{OH}^{*}+\mathrm{H}^{*}
\end{gathered}
$$

However, when the amount of M2 increased over $1.5 \mathrm{~g}$, the degradation efficiency did not change so much. This

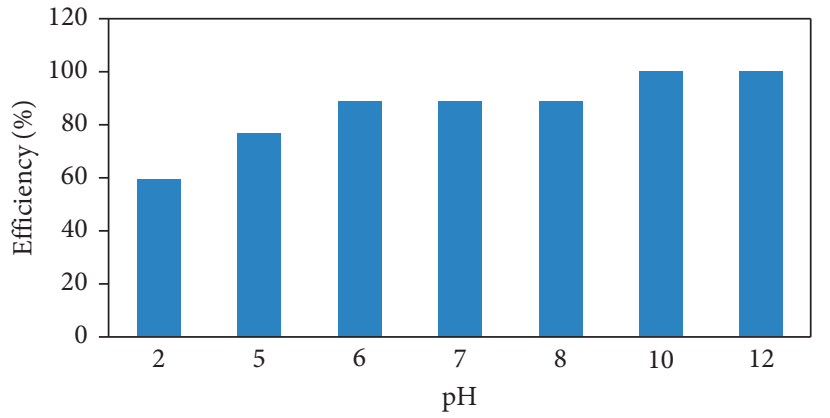

Figure 9: Effect of $\mathrm{pH}$ on the degradation percentage of $\mathrm{MB}$.

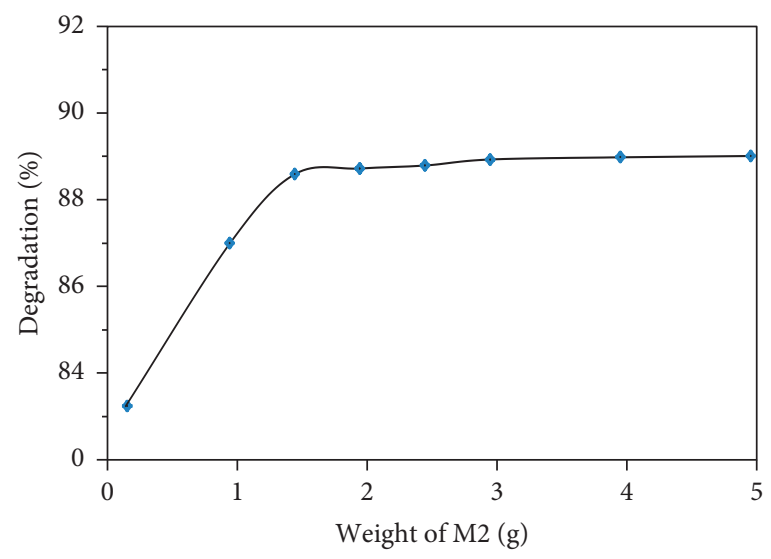

FIgURE 10: The effect of the amount of mixed material M2 on the degradation percentage of $\mathrm{MB}$.

phenomenon is attributed to the scavenging effect of $\mathrm{HO}^{*}$ radicals during unwanted side reactions over the catalyst surface $\mathrm{M} 2$, resulting in a reduction of the availability of $\mathrm{HO}^{*}$ and degradation efficiency [29]:

$$
\begin{gathered}
\mathrm{Fe}^{2+}+\mathrm{OH}^{*} \longrightarrow \mathrm{Fe}^{3+}+\mathrm{OH}^{-} \\
\mathrm{Fe}^{3+}+\mathrm{OOH}^{*} \longrightarrow \mathrm{Fe}^{2+}+\mathrm{O}_{2}+\mathrm{H}^{+} \\
\mathrm{Fe}^{2+}+\mathrm{OOH}^{*} \longrightarrow \mathrm{Fe}^{3+}+\mathrm{OOH}^{-}
\end{gathered}
$$

Thus, in the next survey, we conducted the selection of catalyst amount of about $1.5 \mathrm{~g}$. Moreover, the increase of catalyst dosage should be accompanied by an increase in $\mathrm{H}_{2} \mathrm{O}_{2}$ concentration, and an optimum concentration ratio has to be maintained.

To assess the heterogeneous Fenton catalytic oxidation performance of laterite after coating $\mathrm{MnO}_{2} \mathrm{NP}$ material (M2) in environmental treatment, our group conducted large-scale surveys by preparing one catalytic column with a diameter of $15 \mathrm{~cm}$, height of $15 \mathrm{~cm}$, and weight of $\mathrm{M} 2$ material on the column of about $50 \mathrm{~g}$. The ability degradation $\mathrm{MB}$ of the catalytic column was carried out with $3 \mathrm{~mL}$ $\mathrm{H}_{2} \mathrm{O}_{2} 30 \%$, the initial concentration of methylene blue of $40 \mathrm{mg} / \mathrm{L}$ and flow rate $2 \mathrm{~mL} / \mathrm{min}$. The results of columns processing capacity are given in Table 3 .

The results in Tables 2 and 3 show that the lateritecoating $\mathrm{MnO}_{2}$ nanoparticle material (M2) has both 
TABLE 3: Results of the large-scale surveys on the heterogeneous Fenton catalytic oxidation performance of M2.

\begin{tabular}{lcc}
\hline No. & $V(\mathrm{~mL})$ & Output concentration of MB $(\mathrm{mg} / \mathrm{L})$ \\
\hline 1 & 1200 & - \\
2 & 1000 & - \\
3 & 1000 & 0.21 \\
4 & 1000 & 0.26 \\
5 & 900 & 0.27 \\
6 & 800 & 0.29 \\
6 & 700 & 0.32 \\
7 & 600 & 0.34 \\
8 & 500 & 0.41 \\
9 & 400 & 0.45 \\
10 & 300 & 0.48 \\
11 & 300 & 0.53 \\
12 & 200 & 0.57 \\
13 & 200 & 0.62 \\
14 & 200 & 0.63 \\
15 & 100 & 0.64 \\
16 & 100 & 0.65 \\
17 & 50 & \\
\hline
\end{tabular}

TABLE 4: The degradation efficiency of MB after reusing the catalyst five times.

\begin{tabular}{lccccc}
\hline No. & 1 & 2 & 3 & 4 & 5 \\
\hline Degradation efficiency (\%) & 99.85 & 99.68 & 99.53 & 98.92 & 98.86 \\
\hline
\end{tabular}

adsorption and heterogeneous Fenton catalytic oxidation performances. However, the heterogeneous Fenton catalytic oxidation performance is the domain because the degradation efficiency of $\mathrm{MB}$ after the sample running through the catalytic column almost does not change much and is about $96-100 \%$ (Table 3). This is consistent with that of the previous studies $[1,25,31]$. Specifically, our group has investigated the possibility of catalytic reuse of $\mathrm{M} 2$ material with $3.0 \mathrm{~mL}$ of $30 \% \mathrm{H}_{2} \mathrm{O}_{2}, 10 \mathrm{~L}$ of methylene blue of $40 \mathrm{mg} / \mathrm{L}$, and flow rate $2 \mathrm{~mL} / \mathrm{min}$. The number of reusing the catalyst (M2) is five as shown in Table 4, the degradation efficiency of MB still reaches $98.86 \%$. Therefore, these results prove that heterogeneous Fenton catalytic oxidation performances of the $\mathrm{M} 2$ material with $3.0 \mathrm{~mL} \mathrm{H}_{2} \mathrm{O}_{2} 30 \%$ is completely unaffected after oxidizing $\mathrm{MB}$ and reusing at least five times.

\section{Conclusions}

In conclusion, the adsorption and heterogeneous Fenton catalytic oxidation experiments of laterite-coating manganese dioxide nanoparticle material (M2) were investigated by changing the effective factors such as time, $\mathrm{pH}$, and concentration of $\mathrm{MB}$. The results show that the lateritecoating $\mathrm{MnO}_{2} \mathrm{NP}$ material (M2) shows both adsorption and heterogeneous Fenton catalytic oxidation performances. However, the heterogeneous Fenton catalytic oxidation performance is the domain. Hence, our groups have investigated the ability of catalytic column treatment with high degradation efficiency after the $\mathrm{MB}$ solution running through the column almost does not change much. These results prove that the heterogeneous Fenton catalytic activity of laterite-coating $\mathrm{MnO}_{2} \mathrm{NP}$ material (M2) is completely unaffected by the number of times the MB solution runs through the column. Moreover, this M2 material can be reused five times with the degradation efficiency still being $98.86 \%$. Based on these catalytic performances, the lateritecoating $\mathrm{MnO}_{2} \mathrm{NP}$ material is worthy to be seriously considered in the design of sustainable and readily affordable wastewater treatment solutions in developing tropical countries.

\section{Data Availability}

The data used to support the findings of this study are available from the corresponding author upon request.

\section{Conflicts of Interest}

The authors declare that they have no conflicts of interest.

\section{Acknowledgments}

This research was supported by the researcher program of National University of Civil Engineering, Viet Nam (VL2019/01).

\section{Supplementary Materials}

Figure S1: the calibration graph of MB solution at $\lambda_{\max }$ to about $644 \mathrm{~nm}$. Table S1: the effect of time on adsorption percentage of M2 for MB. Table S2: the effect of MB concentration solution on the adsorption capacity. Table S3: the effect of hydrogen peroxide concentration on the degradation percentage of MB. Table S4: the effect of time on the degradation percentage of MB. Table S5: the effect of $\mathrm{pH}$ on the degradation percentage of MB. Table S6: the effect of the amount of the M2 on the degradation percentage of MB. (Supplementary Materials)

\section{References}

[1] L. Zhang, Y. Nie, C. Hu, and X. Hu, "Decolorization of methylene blue in layered manganese oxide suspension with $\mathrm{H}_{2} \mathrm{O}_{2}$," Journal of Hazardous Materials, vol. 190, no. 1-3, pp. 780-785, 2011.

[2] Z. Yang, Y. Zhang, W. Zhang et al., "Nanorods of manganese oxides: synthesis, characterization and catalytic application," Journal of Solid State Chemistry, vol. 179, no. 3, pp. 679-684, 2006.

[3] M. Rafatullah, O. Sulaiman, R. Hashim, and A. Ahmad, "Adsorption of methylene blue on low-cost adsorbents: a review," Journal of Hazardous Materials, vol. 177, no. 1-3, pp. 70-80, 2010.

[4] C. Xu, G. P. Rangaiah, and X. S. Zhao, "Photocatalytic degradation of methylene blue by titanium dioxide: experimental and modeling study," Industrial \& Engineering Chemistry Research, vol. 53, no. 38, pp. 14641-14649, 2014.

[5] V. K. Gupta and Suhas, "Application of low-cost adsorbents for dye removal-a review," Journal of Environmental Management, vol. 90, no. 8, pp. 2313-2342, 2009.

[6] J.-S. Wu, C.-H. Liu, K. H. Chu, and S.-Y. Suen, "Removal of cationic dye methyl violet $2 \mathrm{~B}$ from water by cation exchange 
membranes," Journal of Membrane Science, vol. 309, no. 1-2, pp. 239-245, 2008.

[7] Y. Li, Q. Du, T. Liu et al., "Comparative study of methylene blue dye adsorption onto activated carbon, graphene oxide, and carbon nanotubes," Chemical Engineering Research and Design, vol. 91, no. 2, pp. 361-368, 2013.

[8] M.-X. Zhu, L. Lee, H.-H. Wang, and Z. Wang, "Removal of an anionic dye by adsorption/precipitation processes using alkaline white mud," Journal of Hazardous Materials, vol. 149, no. 3, pp. 735-741, 2007.

[9] N. Zaghbani, A. Hafiane, and M. Dhahbi, "Separation of methylene blue from aqueous solution by micellar enhanced ultrafiltrationfiltration," Separation and Purification Technology, vol. 55, no. 1, pp. 117-124, 2007.

[10] J. Huang, L. Peng, G. Zeng et al., "Evaluation of micellar enhanced ultrafiltration for removing methylene blue and cadmium ion simultaneously with mixed surfactants," Separation and Purification Technology, vol. 125, no. 214, pp. 83-89, 2014.

[11] G. Sudarjanto, B. Keller-Lehmann, and J. Keller, "Optimization of integrated chemical-biological degradation of a reactive azo dye using response surface methodology," Journal of Hazardous Materials, vol. 138, no. 1, pp. 160-168, 2006.

[12] C. L. Hsueh, Y. H. Huang, C. C. Wang, and C. Y. Chen, "Degradation of azo dyes using low iron concentration of Fenton and Fenton-like system," Chemosphere, vol. 58, no. 10, pp. 1409-1414, 2005.

[13] H. Lim, J. Lee, S. Jin, J. Kim, J. Yoon, and T. Hyeon, "Highly active heterogeneous Fenton catalyst using iron oxide nanoparticles immobilized in alumina coated mesoporous silica," Chemical Communications, vol. 4, pp. 463-465, 2006.

[14] S. Yang, H. He, D. Wu et al., "Decolorization of methylene blue by heterogeneous Fenton reaction using $\mathrm{Fe}_{3-x} \mathrm{Ti}_{x} \mathrm{O}_{4}$ $(0 \leq \mathrm{x} \leq 0.78)$ at neutral $\mathrm{pH}$ values," Applied Catalysis $B$ : Environmental, vol. 89, no. 3-4, pp. 527-535, 2009.

[15] B. H. Hameed, A. L. Ahmad, and K. N. A. Latiff, "Adsorption of basic dye (methylene blue) onto activated carbon prepared from rattan sawdust," Dyes and Pigments, vol. 75, no. 1, pp. 143-149, 2007.

[16] M. Matheswaran and T. Raju, "Destruction of methylene blue by mediated electrolysis using two-phase system," Process Safety and Environmental Protection, vol. 88, no. 5, pp. 350-355, 2010.

[17] Y. Wang, X. Zhang, X. He, W. Zhang, X. Zhang, and C. Lu, "In situ synthesis of $\mathrm{MnO}_{2}$ coated cellulose nanofibers hybrid for effective removal of methylene blue," Carbohydrate Polymers, vol. 110, pp. 302-308, 2014.

[18] P. Gómez-Romero and C. Sanchez, "Hybrid materials, functional applications. an introduction," in Functional Hybrid Materials, Wiley-VCH Verlag GmbH \& Co. KGaA, Weinheim, Germany, 2005.

[19] D. M. Robinson, Y. B. Go, M. Mui et al., "Photochemical water oxidation by crystalline polymorphs of manganese oxides: structural requirements for catalysis," Journal of the American Chemical Society, vol. 135, no. 9, pp. 3494-3501, 2013.

[20] S. Chakrabarti, B. K. Dutta, and R. Apak, "Active manganese oxide: a novel adsorbent for treatment of wastewater containing azo dye," Water Science and Technology, vol. 60, no. 12, pp. 3017-3024, 2009.

[21] X. Liao, C. Zhang, Y. Liu et al., "Abiotic degradation of methyl parathion by manganese dioxide: kinetics and transformation pathway," Chemosphere, vol. 150, pp. 90-96, 2016.

[22] M. Shaban, M. R. Abukhadra, S. S. Ibrahim, and M. G. Shahien, "Photocatalytic degradation and photo-
Fenton oxidation of Congo red dye pollutants in water using natural chromite-response surface optimization," Applied Water Science, vol. 7, no. 8, pp. 4743-4756, 2017.

[23] T. L. P. Dantas, V. P. Mendonça, H. J. José, A. E. Rodrigues, and R. F. P. M. Moreira, "Treatment of textile wastewater by heterogeneous Fenton process using a new composite $\mathrm{Fe}_{2} \mathrm{O}_{3}$ / carbon," Chemical Engineering Journal, vol. 118, no. 1-2, pp. 77-82, 2006.

[24] W. Zhang, Z. Yang, X. Wang, Y. Zhang, X. Wen, and S. Yang, "Large-scale synthesis of $\beta-\mathrm{MnO}_{2}$ nanorods and their rapid and efficient catalytic oxidation of methylene blue dye," Catalysis Communications, vol. 7, no. 6, pp. 408-412, 2006.

[25] Y.-F. Han, F. Chen, K. Ramesh, Z. Zhong, E. Widjaja, and L. Chen, "Preparation of nanosized $\mathrm{Mn}_{3} \mathrm{O}_{4} / \mathrm{SBA}-15$ catalyst for complete oxidation of low concentration $\mathrm{EtOH}$ in aqueous solution with $\mathrm{H}_{2} \mathrm{O}_{2}$," Applied Catalysis B: Environmental, vol. 76, no. 3-4, pp. 227-234, 2007.

[26] R. S. Dassanayake, E. Rajakaruna, H. Moussa, and N. Abidi, "One-pot synthesis of $\mathrm{MnO}_{2}$-chitin hybrids for effective removal of methylene blue," International Journal of Biological Macromolecules, vol. 93, pp. 350-358, 2016.

[27] I. Ahmad, W. A. Siddiqui, and T. Ahmad, "Synthesis, characterization of silica nanoparticles and adsorption removal of $\mathrm{Cu}^{2+}$ ions in aqueous solution," International Journal of Emerging Technology and Advanced Engineering, vol. 7, no. 8, pp. 439-445, 2017.

[28] W. Zhu, W. Jingxuan, D. Wu et al., "Investigating the heavy metal adsorption of mesoporous silica material prepared by microwave synthesis," Nanoscale Reseasch Letter, vol. 12, no. 1 , p. 323, 2017.

[29] G. M. R. Kpinsoton, H. K. Y. Richardson, B. N. Koffil et al., "New insight into the micro structure of natural calcined laterites and their performance as heterogeneous Fenton catalyst form ethylene blue degradation," Reaction Kinetics, Mechanisms and Catalysis, vol. 124, no. 2, pp. 931-956, 2018.

[30] M. E. Becerra, A. M. Suarez, N. P. Arias, and O. Giraldo, "Decomposition of the methylene blue dye using layered manganese oxide materials synthesized by solid state reactions," International Journal of Chemical Engineering, vol. 2018, Article ID 4902376, 11 pages, 2018.

[31] S. Chou and C. Huang, "Application of a supported iron oxyhydroxide catalyst in oxidation of benzoic acid by hydrogen peroxide," Chemosphere, vol. 38, no. 12, pp. 27192731, 1999. 

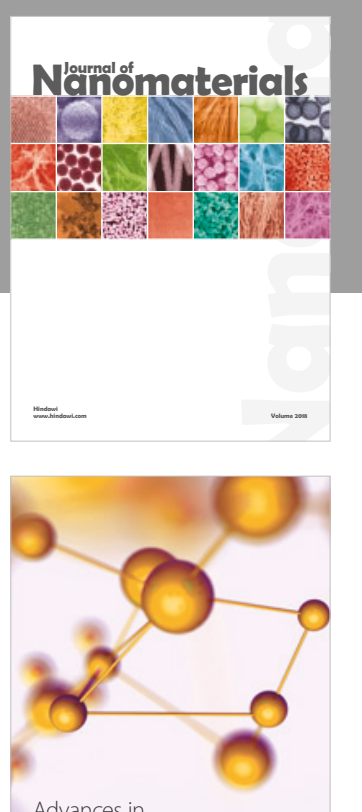

Physical Chemistry
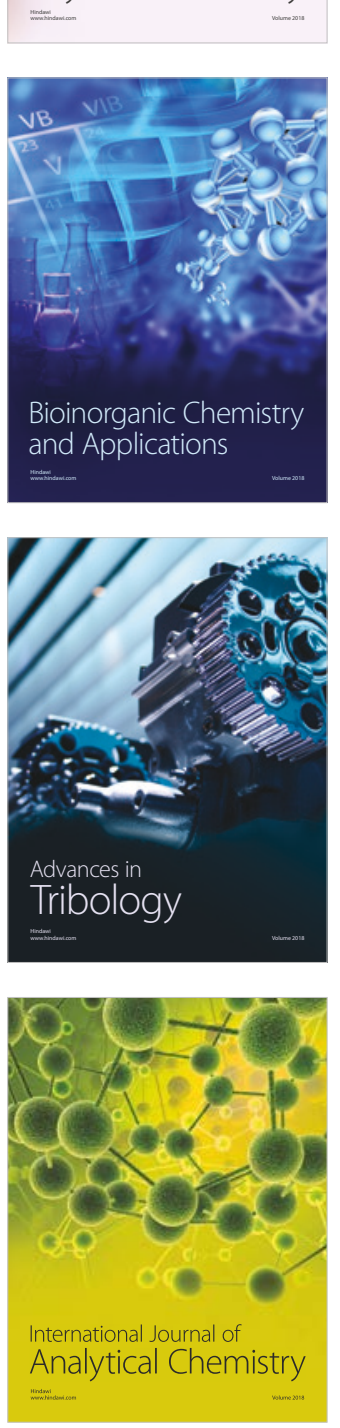

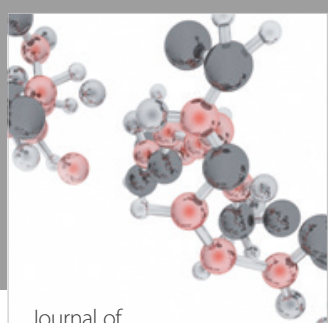

Analytical Methods

in Chemistry

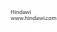

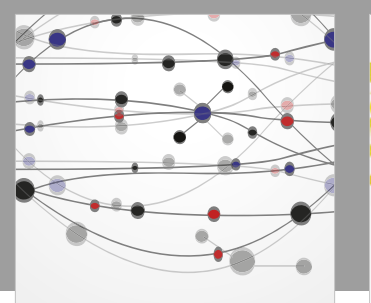

The Scientific World Journal

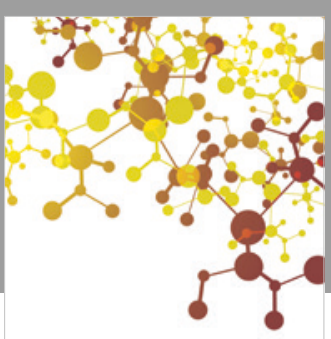

Journal of

Applied Chemistry
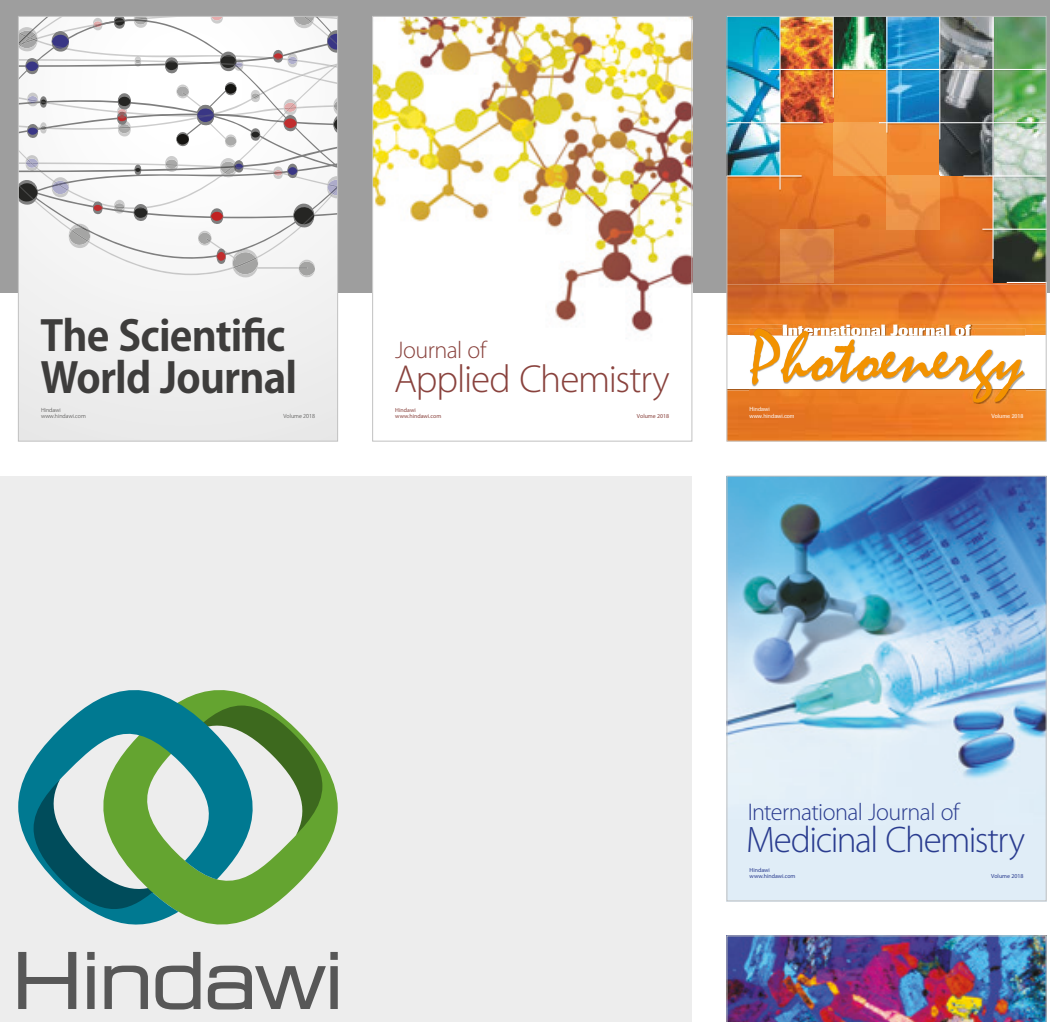

Submit your manuscripts at

www.hindawi.com
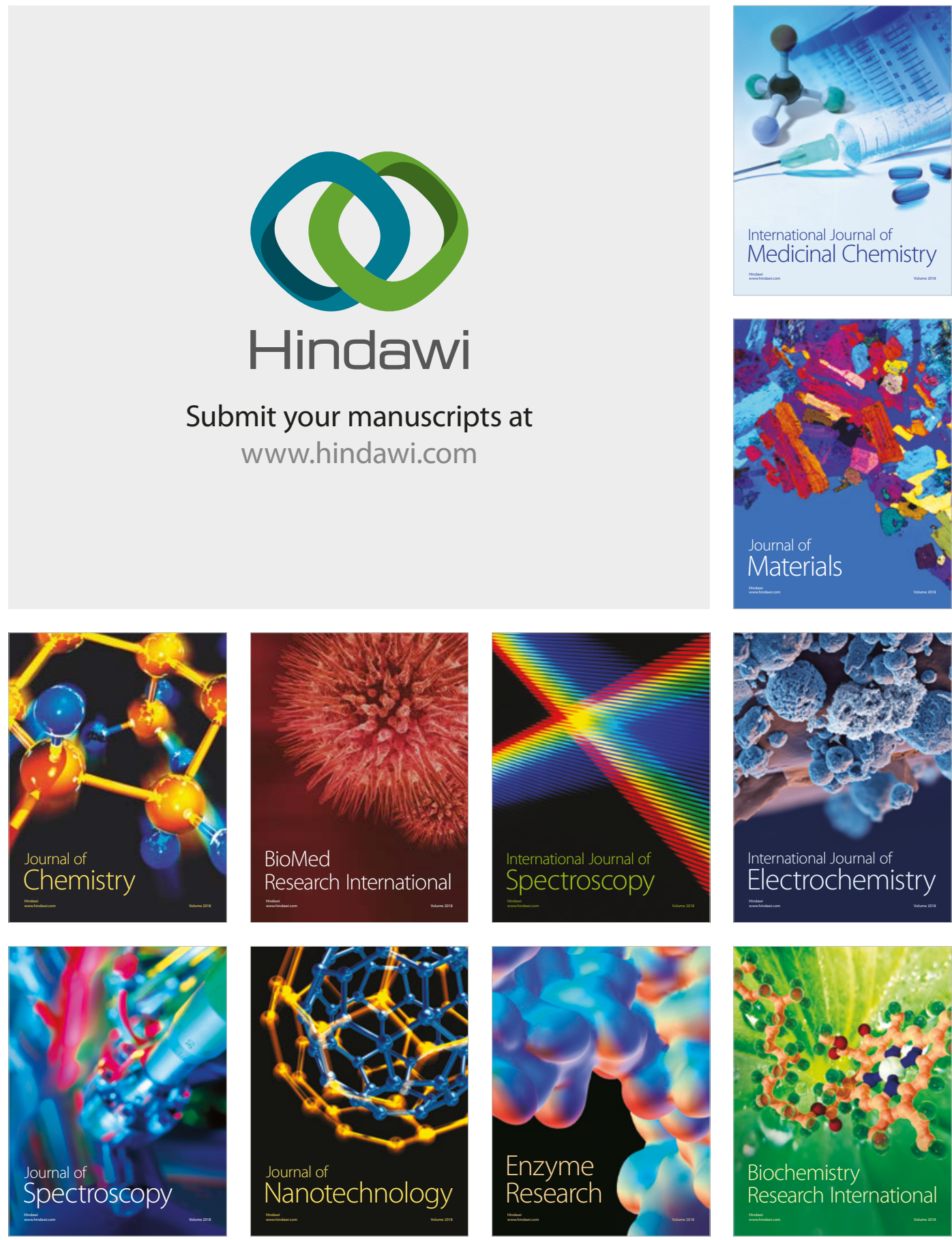
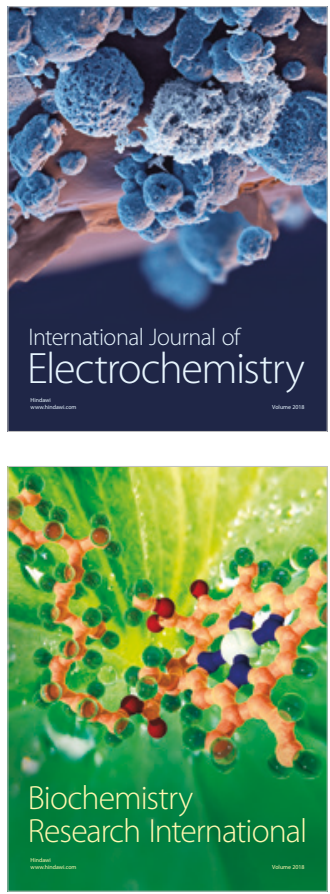